\title{
Description of the Fourth Instar Larva of Lutzomyia longipalpis, under Scanning Electron Microscopy
}

\author{
Antônio Cesar Rios Leite ${ }^{+}$, Paul Williams
}

\begin{abstract}
Departamento de Parasitologia, Instituto de Ciências Biológicas, Universidade Federal de Minas Gerais, Caixa Postal 486, 31270-901 Belo Horizonte, MG, Brasil
\end{abstract}

The fourth instar larva of Lutzomyia (Lutzomyia) longipalpis (Phlebotomidae: Phlebotominae) was studied by scanning electron microscope. Based on three-dimensional observations, the fine structure and setal position (using of setal numeration) of the larva are presented.

Key words. Lutzomyia longipalpis - fourth instar - larva - morphology - chaetotaxy - scanning electron microscopy

Lutzomyia longipalpis (Lutz and Neiva, 1912) is a neotropical Phlebotomidae of medical and veterinary importance. The adult female is the most important invertebrate host (vector) of Leishmania (Leishmania) chagasi, the protozoan responsible for American visceral leishmaniasis (Grimaldi et al. 1989).

Of more than 370 New World phlebotomine species known, L. longipalpis is the best studied vector of American Leishmania. However, the immature stages of this sand fly were only briefly described by Guitton and Sherlock (1969). Using scanning electron microscope (SEM), the egg exochorion (Ward \& Ready 1975) and pupa (Leite et al. 1991) of $L$. longipalpis have been described. Continuing our studies on the immature stages of L. longipalpis, we have used SEM to examine the first instar (unpublished observations) and fourth instar larva of L. longipalpis. Herein, we deal with morphological details of the fourth instar larvae.

\section{MATERIALS AND METHODS}

Fourth instar larvae of L. longipalpis were obtained from a closed laboratory colony. Larvae were killed in hot water $\left(70^{\circ} \mathrm{C}\right)$, fixed in $70 \%$ ethyl alcohol, dehydrated in an ethyl alcohol series, submitted to critical point drying in carbon dioxide, and spattered with colloidal gold.

Description of the setae, except on the head and ninth abdominal segment, are give in an anteriorposterior sequence, beginning from the dorsal midline and working circumferentially in a lateral-ven-

This research was supported, in part, by "Conselho Nacional de Desenvolvimento Científico e Tecnológico" of Brazil.

${ }^{+}$Corresponding author. Fax: 55-031-448.1215

Received 5 December 1995

Accepted 9 February 1996 tral direction. The terminology used for setae is based on, but not identical with, the setal nomenclature of Barretto (1941).

\section{RESULTS}

General appearence of the fourth instar larva - The larva (Fig. 1) is $3.29 \mathrm{~mm}$ long (from the head to the end of the ninth abdominal segment) and with a maximum width of $0.42 \mathrm{~mm}$ at metathorax. Except on the head and the last segment, the larval integument is usually covered by small tubercles, which are without spines on the dorsal surface but with spines on the lateral and ventral surfaces. Both dorsal and lateral surfaces of the thoracic and the first seven abdominal segments, have narrow and bare areas (isolated or contiguous) surrounded by minute tubercles (Fig. 20). Barbed brush-like setae, distributed in pairs, predominate on the larval body, but simple (bare) paired setae are also present. Each element of the barbed setae has pointed tips. A few small papillae or sensillae are present on the head and abdominal segments.

Head - On the head (Figs 2, 3), the anterior setae are simple or bare, without a prominent basal tubercle, and the posterior setae are barbed or brush-like, and inserted on a tubercle. The posterior part of the head is covered by minute spines, which usually form a polygonal figure on the integument; ventrally the minute spines are scarce and are arranged in rows (Fig. 4). The mouthparts (Fig. 5) are of a chewing type. The labrum (Fig. 6) has many fringes; each mandible (Figs 3 and 8) bears two simple setae and, ventrally, four strong teeth; the dorsum of the labium (Fig. 5) has four pairs of strong teeth; each maxilla (Fig. 7) carries two bare setae, a maxillary process or, possibly, a sensillum, a small sensillum-like, papilliform structure, on the maxillary palp, and spinose hairs (Fig. 8 ). The oral cavity is covered internally with fine 

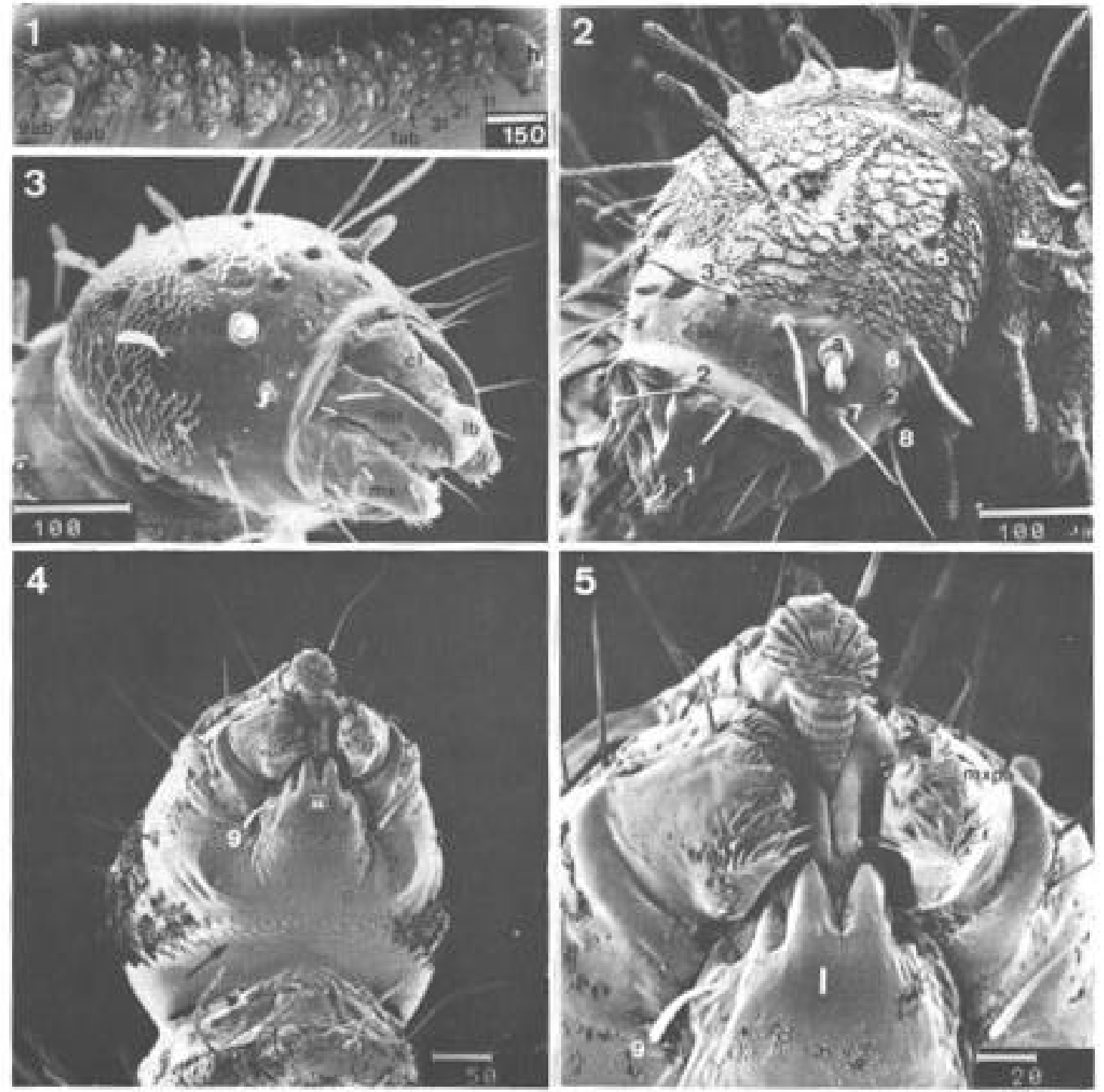

Scanning electron micrographs of the fourth instar larva of Lutzomyia longipalpis. Fig. 1: entire body in lateral view. Fig. 2: head in dorsal view. Fig. 3: head in lateral view. Fig. 4: head, showing the spinules (arrow), in ventral view. Fig. 5: mouthparts in frontal view. $\mathrm{Bar}=\mu \mathrm{m}$. Abbreviations: $\mathrm{a}=$ antenna, $\mathrm{cl}=$ clypeus, $\mathrm{h}=$ head, $\mathrm{l}=\mathrm{labio}, \mathrm{r}=$ labrum, $\mathrm{m}=$ mentum, $\mathrm{mn}=$ mandible, $\mathrm{mx}=$ maxilla, $\mathrm{mxpa}=$ maxillary palp, $1 \mathrm{ab}$ to $9 \mathrm{ab}=$ first to ninth abdominal segments, $1 \mathrm{t}$ to $3 \mathrm{t}=$ first to third thoracic segments, $1=$ anterior clypeal seta, $2=$ posterior clypeal seta, $3=$ anterior frontal seta, $4=$ posterior frontal seta, $5=$ dorsal vertical seta, 6 $=$ lateral vertical seta, $7=$ dorsal genal seta, $8=$ lateral genal seta, $9=$ ventral genal seta .

hairs (Fig. 6). The labio-hypopharynx (Fig. 8) bears distinctive groups of teeth: ventral premental, lateral premental, prementolingular, and premental cusps. Each antenna (Fig. 9) has a basal socket, a small, cylindrical first segment fused to a ovoid second segment (distal). This latter bears a bifurcated structure on the posterior surface and three

\footnotetext{
': simple seta; +: little barbed seta; *: barbed seta
}

short and one long structures that are probable sensilla. The apex has a small appendage. The head, excluding the hears on the maxilla and mandible, has nine pairs of the setae: anterior clypeal (1)', posterior clypeal (2)', anterior frontal (3)+, posterior frontal (4)* (Fig. 10), dorsal vertical (5)*, lateral vertical (6)*, dorsal genal (7)', lateral genal (8)', and ventral genal (9)'.

Prothorax - This segment has the appearance of two segments. Anterior and posterior regions are recognizable. The following terminology is the 

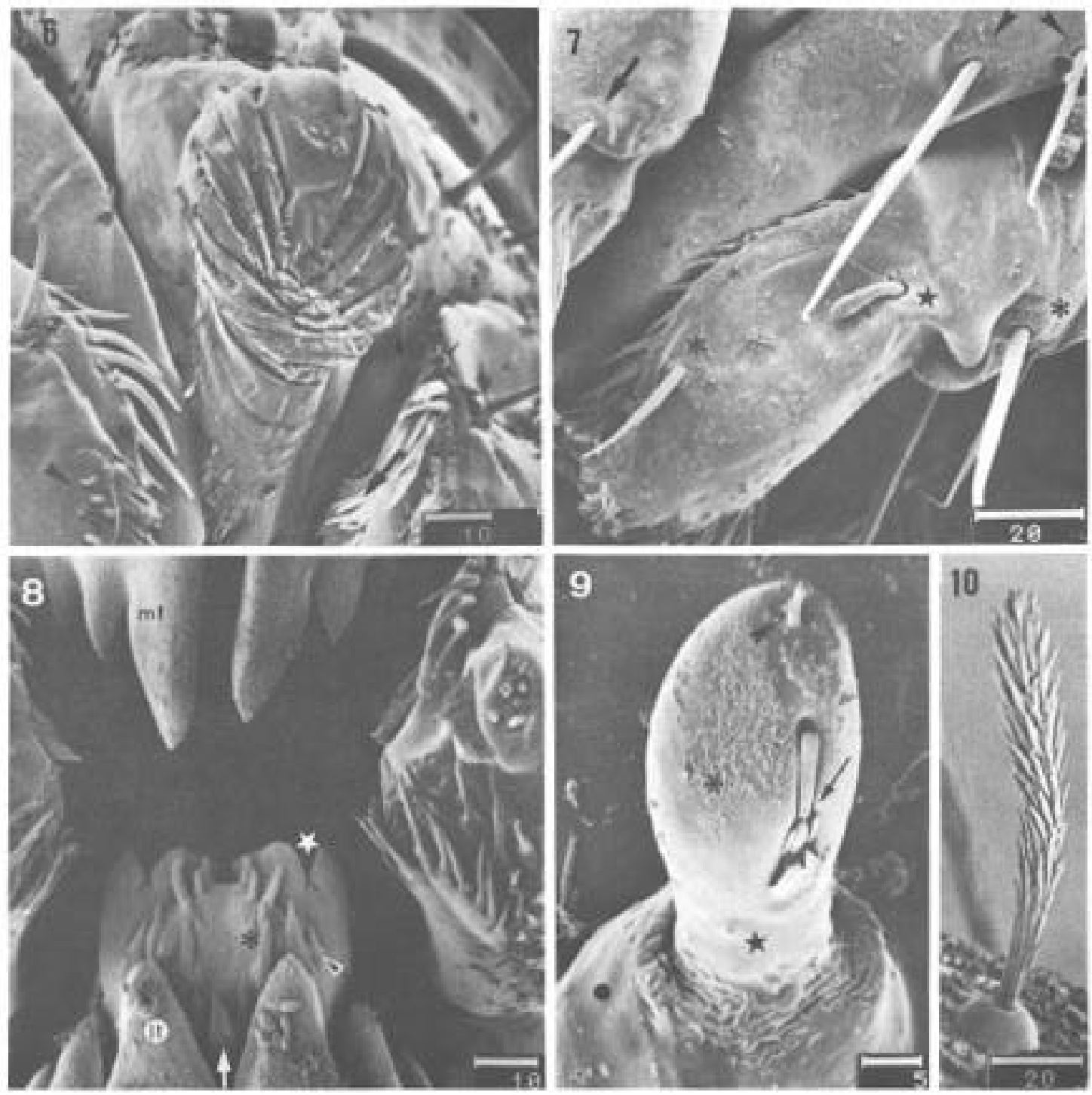

Scanning electron micrographs of the fourth instar larva of Lutzomyia longipalpis. Fig. 6: labrum in frontal view; note the internal oral hairs (arrow) and the probable maxillary palp sensilla (arrow head). Fig. 7: posterior clypeal seta (arrow), mandibular seta (arrow head), maxillary seta (asterisk), and maxillary process or sensillum (star). Fig. 8: part of the labio-hypopharynx showing lateral premental teeth (arrow head), premental cusps (star), prementolingular teeth (asterisk), and ventral premental teeth (arrow). Fig. 9: antenna in posterior view, showing the antennal socket (circle), the first antennal segment (star), the second antennal segment (asterisk), the probable sensillae (arrow), and the apical appendage or probable sensillum. Fig. 10: posterior frontal seta of the head. Bar $=\mu \mathrm{m}$. Abbreviations: $1 \mathrm{t}=$ labrum teeth, $\mathrm{mt}=$ mandibular teeth.

most convenient for designating setae: internal anterior dorsal $(1)^{*}$, intermediate anterior dorsal $(2)^{*}$, external anterior dorsal (3)*, anterior lateral accessory (a)', pre-anterior lateral (4)* (Fig.12), postanterior lateral (5)*, small post-anterior lateral (6)*, intermediate anterior ventral (7)+, internal anterior ventral (8)+, internal posterior dorsal (9)*, intermediate posterior dorsal $(10)^{*}$, external posterior dorsal (11)*, posterior lateral (12)* (Fig. 11), external posterior ventral (13)*, intermediate poste- rior ventral $(14)^{*}$, small intermediate posterior ventral (15)*, and internal posterior ventral (16)*. The anterior spiracle (Figs 11, 14) is below the posterior lateral seta, and has a central depression and eleven papilla, each with a small slit-like opening. Setae of the ventral side are shown in Figs 1518.

Meso- and Metathorax - These two segment are similar to one another and have identical arrangements of setae: internal dorsal $(1)^{*}$, interme- 

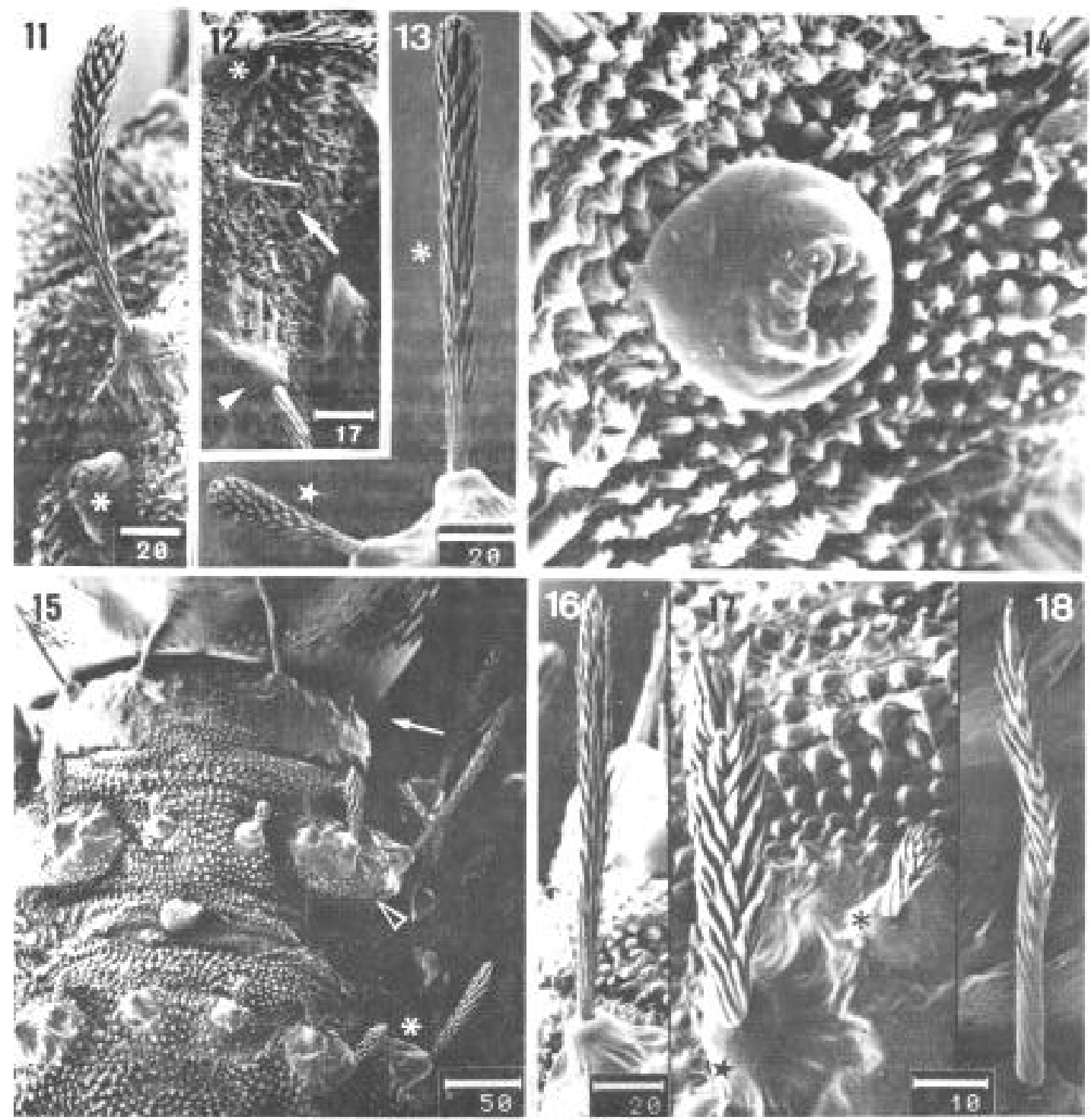

Scanning electron micrographs of the fourth instar larva of Lutzomyia longipalpis. Fig. 11: posterior lateral prothoracic seta and anterior spiracle (asterisk). Fig. 12: external anterior dorsal seta (asterisk), anterior lateral accessory seta (arrow) and pre-anterior lateral seta (arrow head) of the prothorax. Fig. 13: pre-anterior lateral seta (asterisk) and post-anterior lateral seta (star) of the metathorax. Fig. 14: anterior spiracle. Fig. 15: prothorax and mesothorax in ventral view, showing the anterior ventral prothoracic setae (arrow), posterior ventral prothoracic setae (arrow head) and ventral mesothoracic setae (asterisk). Fig. 16: external posterior ventral prothoracic seta. Fig.17: intermediate posterior ventral seta (star) and small intermediate posterior ventral seta (asterisk) of the prothorax. Fig. 18: internal anterior ventral prothoracic seta. Bar $=\mu \mathrm{m}$.

diate dorsal (2)*, external dorsal (3)*, lateral accessory (a)', anterior lateral (4)*, posterior lateral $(5)^{*}$, small posterior lateral (6)*, external ventral $(7)^{*}$, intermediate ventral $(8)^{*}$, small intermediate ventral (9)*, and internal ventral (10)*. Setae of the ventral side are pictured in Fig. 15.

First to seventh abdominal segments - All segments exhibit a similar morphology and identical setal topography: small internal dorsal (1)*, inter- nal dorsal (2)*, intermediate dorsal (3)*, external dorsal (4)*, anterior lateral (5)*, posterior lateral (6)*, small porterior lateral (7)*, anterior ventral (8)', and posterior ventral (9)'. Abdominal setae are shown in Figs 19-21. Each pseudopodium (Figs 21 and 24) bears four sensilla on the smooth area and two sensilla on the wrinkled area.

Eighth abdominal segment - This segment has seven setal pairs: internal dorsal (1)*, interme- 

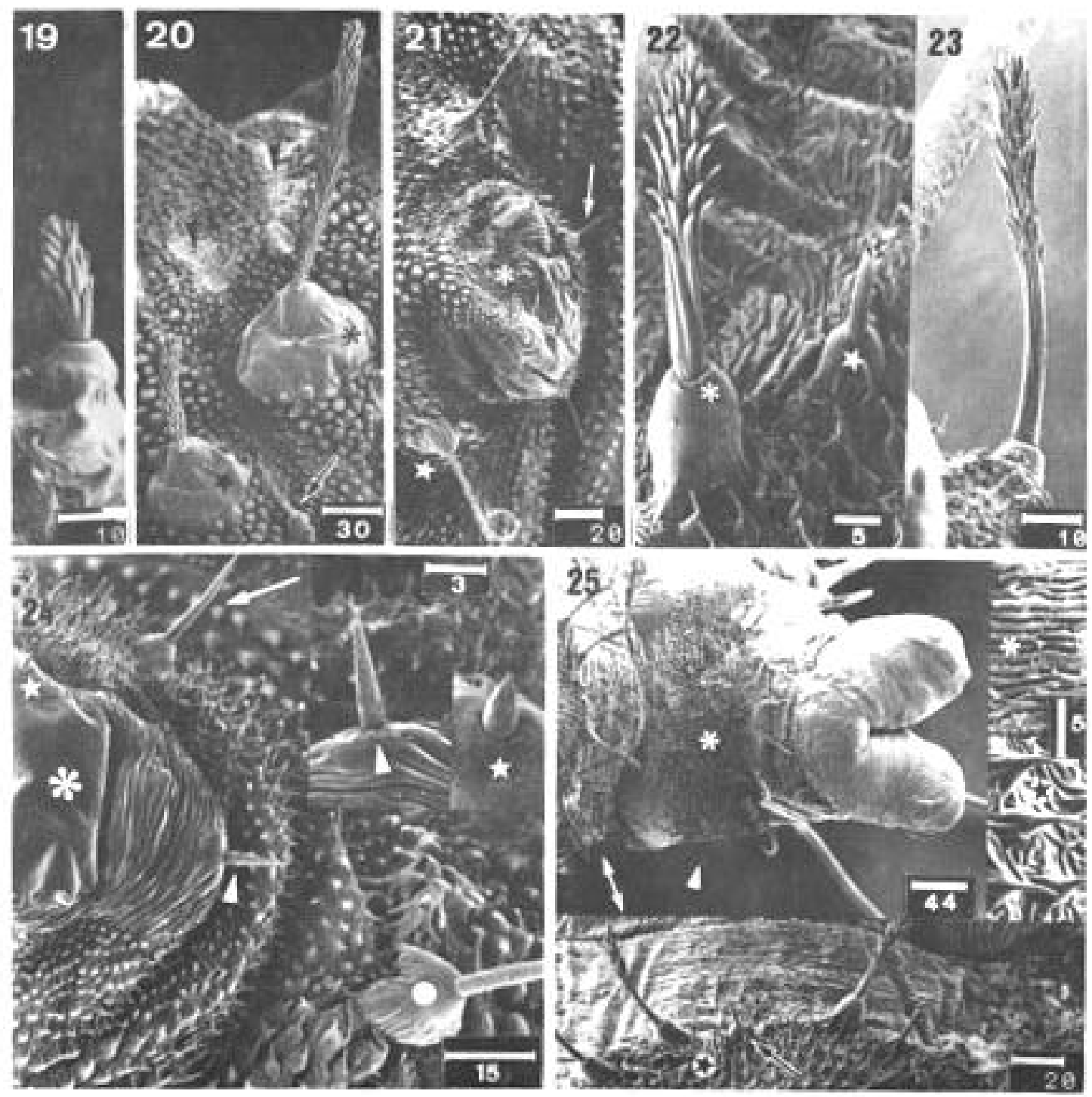

Scanning electrom micrographs of the fourth instar larva of Lutzomyia longipalpis. Fig. 19: small internal dorsal seta of the sixth abdominal segment. Fig. 20: anterior lateral (asterisk), posterior lateral (star) and small posterior lateral (arrow) setae of the seventh abdominal segment; note the bare areas on dorsal surface of the segment (arrow head). Fig. 21: pseudopodium (asterisk) and ventral anterior (arrow) and ventral posterior (star) setae of the first abdominal segment. Fig. 22: internal ventral (asterisk) and intermediate ventral (star) setae of the eighth abdominal segment. Fig. 23: posterior caudal seta. Fig. 24: pseudopodium (asterisk) showing the probable sensillum in low and high magnifications (star and arrow head), and the anterior ventral (arrow) and posterior ventral (circle) setae. Fig. 25: posterior edge of the eighth (double head arrow) and ninth abdominal segment (arrow head) in ventral view; note the marks (asterisk and star) showing the areas in low and high magnifications, and the atypical position of an intermediate ventral seta (arrow). Bar $=\mu \mathrm{m}$.

diate dorsal (2)*, lateral accessory ( a)', external dorsal (3)*, external ventral (4)*, intermediate ventral (5)*, small intermediate ventral (6)* (Fig. 22), and internal ventral (7)* (Fig. 22). Atypical position of the seta 5 can be observed (Fig. 25) on the segment. The posterior spiracle (Fig. 27), has a central depression and sixteen papilla, each one with a small slit-like opening.
Ninth abdominal segment - The last segment (Figs 25, 26) exhibits a different morphology from those preceding segments. It is, dorsally, covered by spinules and carries two prominent caudal lobes, each with two caudal setae, two lobular caudal setae and one campaniform sensillum (Fig. 29). On the ventral side, the segment bears several grooves. The two anal lobes (Fig. 28) are smooth and wrikled 

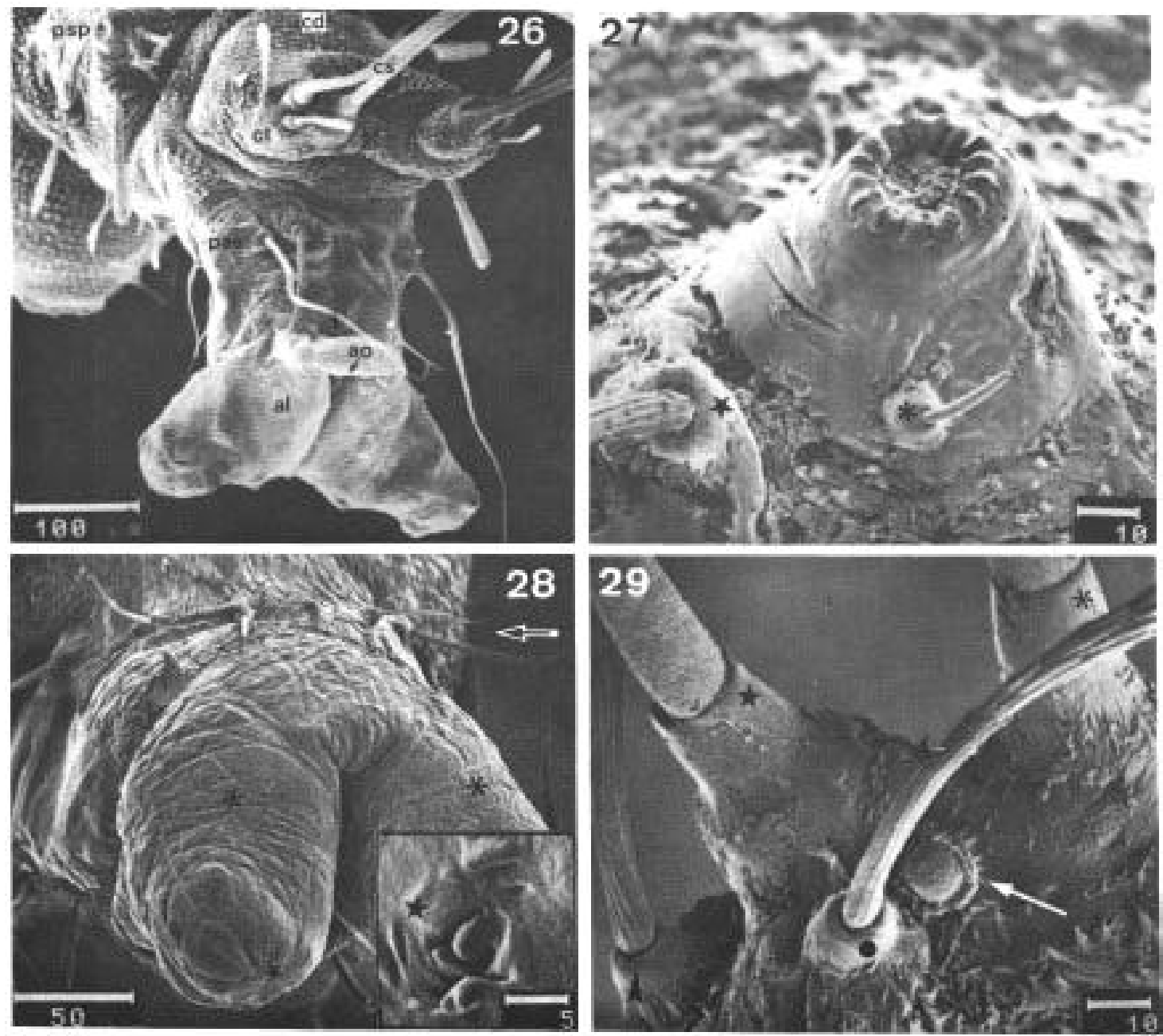

Scanning electron micrographs of the fourth instar larva of Lutzomyia longipalpis. Fig. 26: posterior end of the larva in lateral terminal view. Fig. 27: posterior spiracle, accessory seta (asterisk) and dorsal external seta (star) in lateral posterior view. Fig. 28: anal lobes (asterisk) and pre-anal setae (arrow) in lateral terminal view, note the probable sensorial pit (star, in low and hight magnifications). Fig. 29: caudal tubercle showing the internal caudal (asterisk) and external caudal (star) setae, beside the anterior caudal (arrow head) and posterior caudal (circle) setae, and a probable campaniform sensillum (arrow). Bar $=\mu \mathrm{m}$. Abbreviations: an $=$ anal lobe, ao $=$ anal opening, at $=$ anal tubercle, $c d=$ caudal depression, $c s=$ caudal setae, pas $=$ post-anal setae, $\mathrm{psp}=$ posterior spiracle.

in different areas, and have some sensilla. On the segment the pairs of setae are as following: anterior lobular caudal (1)*, internal caudal (2)', external caudal (3)', posterior lobular caudal (4)*, intermediate post-anal (5)', external post-anal (6)', external pre-anal (7)', intermediate pre-anal (8)', and internal pre-anal (9)'.

\section{DISCUSSION}

The fourth instar larvae of New World plebotomines have been described on the basis of light microscope studies by several authors (Barretto 1941, Mangabeira 1942 a-e, Sherlock, 1957 a-b, Mangabeira \& Sherlock 1962, Sherlock \& Carneiro 1963, Hanson 1968, Guitton \&
Sherlock 1969, Ward 1972, 1976 a-b. However, only Guitton and Sherlock (1969) described the larval stages of $L$. longipalpis.

The names of setae on larvae of American sand flies was introduced by Barretto (1941). This terminology, sometimes with modifications has been most frequently used (Hanson 1968, Ward 1972, Forattini 1973). Forattini (1973) as well as using the terminology of Barretto (1941), adopted the numerical chaetotaxy elaborated by Abonnenc (1956) for the larvae of Old World sand flies.

Ward (1976a) found the terminology available at the time to be inadequate for studies (Ward 1976b) on the larvae of species belonging to the subgenera Nyssomyia Barretto, 1962 and 
Psychodopygus Mangabeira, 1942 of the genus Lutzomyia. The terminology introduced by Ward (1976a) and used by Ward (1976b) was the result of studies, including three-dimentional observations, on the homologies of setae of the thoracic and abdominal segments. It was admitted (Ward 1976b) that the descriptive terms proposed might be of use only for the subgenera he studied. In our experience, it is difficult to apply the scheme proposed by Ward (1976a) as the basis for describing larvae of L. longipalpis. For this reason we have used a terminology based on that of Barretto (1941).

On the available evidence, fourth instar larvae of New World phlebotomines can be placed in four categories, on the basis of the appearance of the antennae. Group 1: antennal tubercle (socket) with the appearence of an elongate cone; basal segment short or subegual to the distal segment. Group 2: antennal tubercle in the form of the troncated cone; basal segment short; distal segment bana-shaped. Group 3: antennal tubercle with the shape of a truncated cone; basal segment long or subequal to the distal segment; distal segment digitiform but short. Group 4: antennal tubercle annular; basal segment short, distal segment ovoid.

From the results presented herein, and from the optical microscope studies of Guitton and Sherlock (1969), the fourth instar larva of L. longipalpis belongs to the fourth category. It should be emphasized, however, that the four categories cannot be related to contemporary classification schemes based on characters of adults. For exemple, Young and Duncan (1994) placed L. longipalpis, L. renei Martins, Falcão and Silva, 1957, L. lichyi Floch and Abonnenc, 1957 and L. gomezi Nitzulescu, 1930 within the subgenus Lutzomyia s.st. França, 1924. Such placement may be justified on the basis of adult morphology but the distal antennal segment of the fourth instar larvae of $L$. longipalpis and $L$ rene $i$ are ovoid (Sherlock $1957 \mathrm{~b}$ and present observations) while that of L. lichyi and L. gomezi are digitiform (Hanson 1968).

The foregoing comment suggests that additional studies on the morphology of immature phlebotomines, preferably by means of scanning electronic microscopy, would provide useful information in re-evaluating concepts on the systematics of New World phlebotomines and, indeed, of Phlebotomidae on a world-wide basis.

In the present report, occasional reference has been made to sensilla on the larvae integument. These are structures that, hitherto, have been little used in studies on the taxonomy and systematics of Phlebotomidae. Futher use of electron microscopy, to study both immature and adult phlebotomines, could possibly reveal that the mor- phology of sensilla, and the distribution of sensilla of different types, could be of systematic utility.

\section{AKNOWLEDGMENTS}

To "Centro de Microscopia Eletrônica do ICBUFMG" for the use of the scanning electron microscope.

\section{REFERENCES}

Abonnenc E 1956. L'óeuf et les formes larvaires de deux phlebotomes africains: $P$. antennatus var. occidentalis Theodor, 1933 et P. dubius Parrot, Mornet et Cardenat, 1945. Arch Inst Pasteur d'Alger 34: 518-539.

Barretto MP 1941. Morfologia dos ovos, larvas e pupas de alguns flebótomos de São Paulo. An Fac Med Univers São Paulo 17: 356-427.

Forattini OP 1973. Entomologia médica: Psychodidae. Phlebotominae. Leishmaníases. Bartonelose. Editora Blücher Ltda, Editora da Universidade de São Paulo, São Paulo, 658 pp.

Grimaldi Jr G, Tesch RB, McMahon-Pratt D 1989. A review of the geographic distribuition and epidemiplogy of leishmaniasis in the New World. Am J Trop Med Hyg 41: 687-725.

Guitton N, Sherlock IA 1969. Descrição das fases imaturas do Phlebotomus longipalpis Lutz e Neiva, 1912 (Diptera, Psychodidae). Rev Bras Biol 29: 383389.

Hanson WJ 1968. The immature stages of the subfamily Phlebotominae in Panama (Diptera: Psychodidae). Ph.D. thesis, University of Kansas,University Microfilms Inc., Ann Arbor, Michigan, 104 pp. +27 pls.

Leite ACR Williams P, Santos MC 1991. The pupa of Lutzomyia longipalpis (Diptera: Psychodidae Phlebotominae). Parassitologia 33: 477-484.

Mangabeira O 1942a. $8^{\text {a }}$ contribuição ao estudo dos Phlebotomus (Diptera:Psychodidae) Phlebotomus (Brumptomyia) avellari Costa Lima,1932. Mem Inst Oswaldo Cruz 37: 225-240.

Mangabeira O 1942b. $9^{\mathrm{a}}$ contribuição ao estudo dos Phlebotomus (Diptera:Psychodidae) Phlebotomus (Pressatia) triacanthus Mangabeira, 1942. Mem Inst Oswaldo Cruz 37: 241-250.

Mangabeira O 1942c. $10^{\mathrm{a}}$ contribuição ao estudo dos Phlebotomus (Diptera: Psychodidae) Phlebotomus longispinus Mangabeira, 1842. Mem Inst Oswaldo Cruz 37: 251-257.

Mangabeira O 1942d. $11^{\mathrm{a}}$ contribuição ao estudo dos Phlebotomus (Diptera: Psychodidae) Phlebotumus oswaldoi Mangabeira, 1942. Mem Inst Oswaldo Cruz 37: 287-295.

Mangabeira O 1942e. 13 contribuição ao estudo dos Phlebotomus (Diptera: Psychodidae) Phlebotomus (Brumptomyia) travassosi Mangabeira, 1942. Mem Inst Oswaldo Cruz 37: 375-381.

Mangabeira O, Sherlock IA 1962. Sobre o Phlebotomus brasiliensis Costa Lima, 1932 (Diptera: Psychodidae). Mem Inst Oswaldo Cruz 60:311-319.

Sherlock IA 1957a. Sobre o "Phlebotomus lenti" Mangabeira, 1936 (Diptera: Psychodidae). Rev Bras Biol 17: 77-88. 
Sherlock IA 1957b. Sobre o "Phlebotomus renei" Martins, Falcão \& Silva, 1956 (Diptera: Psychodidae). Rev Bras Biol 17: 547-556.

Sherlock IA, Carneiro M 1963. Descrição das fases imaturas de Phlebotomus bahiensis Mangabeira \& Sherlock, 1964 (Diptera: Psychodidae). Mem Inst Oswaldo Cruz 61: 491-494.

Ward RD 1972. Some observations on biology and morphology of the immature stages of Psychodopygus wellcome Fraiha, Show and Lainson, 1971 (Diptera: Psychodidae). Mem Inst Oswaldo Cruz 70:15-28.

Ward RD 1976a. A revised numerical chaetotaxy of neotropical phlebotomines sandfly larvae (Diptera: Psychodidae). Syst Entomol 1: 89-94.

Ward RD 1976b. The immature stages of some Phlebotominae sandflies from Brazil (Diptera: Psychodidae). Syst Entomol 1: 227-240.

Ward RD, Ready PA 1975. Chorionic sculturing in some sandflies from Brazil (Diptera: Psycodiadae). $J$ Entomol 50: 127-134.

Young DG Duncan MA 1994. Guide to the identification and geographic distribution on Lutzomyia sand flies in Mexico, the West Indies, Central and South America (Diptera: Psychodidae). Mem Am Entomol Inst 54: 1-875. 